\title{
(46.5) \\ Characterization of Anodic Films on AZ31 Magnesium Alloys in Alkaline Solutions Containing Fluoride and Phosphate Anions
} $0013-4651 / 2006 / 153(10) / B 417 / 8 / \$ 20.00$ () The Electrochemical Society

\author{
C. S. Lin $^{*, z}$ and Y. C. Fu
}

Department of Materials Science and Engineering, National Taiwan University, Taipei 106, Taiwan

AZ31 magnesium alloys were galvanostatically anodized in an alkaline solution without and with the addition of phosphate and fluoride ions. The microstructure and composition of the anodic film were investigated using cross-sectional transmission electron microscopy. Results show that during anodizing at $10 \mathrm{~mA} \mathrm{~cm}{ }^{-2}$ in the $\mathrm{KOH}$ solution, the potential of the cell was relatively low and sparks were absent throughout the anodization. Adding fluoride ions in the $\mathrm{KOH}$ solution resulted in a sharp increase in cell voltage during the early stages of anodizing and subsequent sparking commenced at $\sim 75 \mathrm{~V}$. In contrast, phosphate ions in the solution hardly affected the potential response of the cell. The anodic film formed in the presence of fluoride ions consisted of a compact inner layer containing significant fluorine species, while that formed in the solution without fluoride ions comprised a highly porous inner layer. Sparking, which resulted from the dielectric breakdown of the compact inner layer, led to the formation of magnesium oxide layer. In contrast, the anodic film formed in the absence of sparks was primarily the magnesium hydroxide. (C) 2006 The Electrochemical Society. [DOI: 10.1149/1.2257987] All rights reserved.

Manuscript submitted March 21, 2006; revised manuscript received June 5, 2006. Available electronically August 8, 2006.

Anodization treatment has been used extensively to modify the surface of magnesium alloys with better corrosion resistance, higher hardness, and improved decorative and wear-resistance properties, as well as enhanced paint adhesion. ${ }^{1-5}$ Anodization of magnesium can be carried out in acid or alkaline media using the direct or alternating currents. DOW17 and HAE are, respectively, the typical processes performed in acid and alkaline media, in which fluoride and phosphate ions are the common ions for both solutions. ${ }^{6,7} \mathrm{Al}-$ though the DOW17 process produces anodic films displaying excellent corrosion protective properties, environmental concerns about the use of hexavalent chromium have stimulated the development of chromate-free anodization solutions. Recently, several industrial processes performed in nonchromate solutions have been realized, such as Tagnite, Anomag, Magoxid-Coat and Keronite processes, which are conducted in neutral or alkaline solutions with the addition of fluoride, borate, sulfate, phosphate, aluminate, and silicate. ${ }^{3,5,8-10}$

The properties of anodic films on magnesium can be closely related to its microstructure and composition, which depend largely on the composition of the electrolyte and the anodizing parameters of the process. For example, $\mathrm{Mg}-\mathrm{Al}$ alloys can be passivated in a $1 \mathrm{M}$ sodium hydroxide solution during constant voltage anodizing in both the low-voltage (less than $3 \mathrm{~V}$ ) and high-voltage ranges $(10$ to $80 \mathrm{~V}){ }^{2,11,12}$ Passivation of the alloys anodized at 3 and $80 \mathrm{~V}$ is, respectively, due to the coverage of magnesium hydroxide and oxide layers, in which the hydroxide layer is thicker than the oxide layer. ${ }^{12}$ Consequently, the anodic film formed at $3 \mathrm{~V}$ exhibits better corrosion resistance than that formed at $80 \mathrm{~V}$. Anodic films formed in the solution composed of hydroxide, silicate, and fluoride of potassium contain smaller and less-interconnected pores, which are more uniform in size and distribution, than those formed using HAE or Dow 17 processes. ${ }^{3}$ Consequently, the resultant anodic films exhibit better corrosion resistance than those formed using HAE or Dow17 processes. Recently, both aluminate in the electrolyte and aluminum in the alloy have been shown to increase the aluminum content of the anodic film on magnesium alloys anodized in $\mathrm{KOH}$ aluminate solutions. ${ }^{13-16}$ Thicker anodic films can be obtained after sparking in a solution containing higher aluminate content. Silicate ions in alkaline solutions also enhance the breakdown potential of the anodic film, giving rise to thicker films with improved corrosion resistance. $3,4,17,18$

Detailed microstructure of the anodic film on aluminum have led to the understanding of its formation mechanism, allowing the de-

* Electrochemical Society Active Member

z E-mail: csclin@ntu.edu.tw velopment of new electrolytes or tailoring the processing parameters associated with the existing electrolytes. ${ }^{1,19,20}$ Compared with that on aluminum, the microstructure of the anodic film on magnesium is less well studied. By using cross-sectional transmission electron microcopy (TEM), this present study details the microstructure of the anodic film on AZ31 magnesium alloys in alkaline solutions containing fluoride and phosphate anions, which are the common ions frequently added in the solutions available in the literature.

\section{Experimental}

Anodization treatment.- The material used in this study is the commercial AZ31 plate. The coupons with a size of $50 \times 20$ $\times 2 \mathrm{~mm}$ were mechanically polished using abrasive emery paper up to 1200 grit, rinsed with deionized water, cleaned in acetone ultrasonically, and finally dried in a stream of hot air. The electrolyte was based on $3 \mathrm{M}$ potassium hydroxide $(\mathrm{KOH})$ with the addition of $0.6 \mathrm{M}$ potassium fluoride $(\mathrm{KF})$ and $0.21 \mathrm{M}$ trisodium phosphate $\left(\mathrm{Na}_{3} \mathrm{PO}_{4}\right)$, of which concentration followed that reported in Ref. 2 and 13-16. Anodization was carried out galvanostatically at a current density of $10 \mathrm{~mA} \mathrm{~cm}^{-2}$ in the solution at room temperature. Temperature and air above the solution were not regulated during anodizing. An AZ31 plate and a high density graphite plate were employed as the anode and cathode, respectively. Each plate was generally anodized for $10 \mathrm{~min}$, during which the potential between the anode and cathode was monitored and recorded using an oscilloscope. After anodizing, the plate was thoroughly rinsed in deionized water and then left for drying in room temperature air overnight.

Microstructural characterization.- The crystallinity and phase of the anodic film were identified using glancing-angle X-ray diffraction (XRD). The surface morphology of the film was investigated using a scanning electron microscope (SEM). Cross-sectional TEM was employed to investigate the detailed microstructure of the film, including the composition analyses by EDS using an electron probe of $10 \mathrm{~nm}$ in diameter and the crystal structure identification by the selected area electron diffraction technique.

\section{Results}

Potential response.- - Figure 1 shows the cell potential as a function of the anodizing time for the plates anodized in the various solutions. In a $3 \mathrm{M} \mathrm{KOH}$ solution, the potential was relatively small, $\sim 3 \mathrm{~V}$, and remained relatively unchanged throughout the anodization treatment (Fig. 1a). Adding $\mathrm{Na}_{3} \mathrm{PO}_{4}$ to the $\mathrm{KOH}$ solution brought about insignificant change in the potential-time curve (Fig. $1 b)$.

In contrast, when $\mathrm{KF}$ was added to the $\mathrm{KOH}$ solution, the poten- 


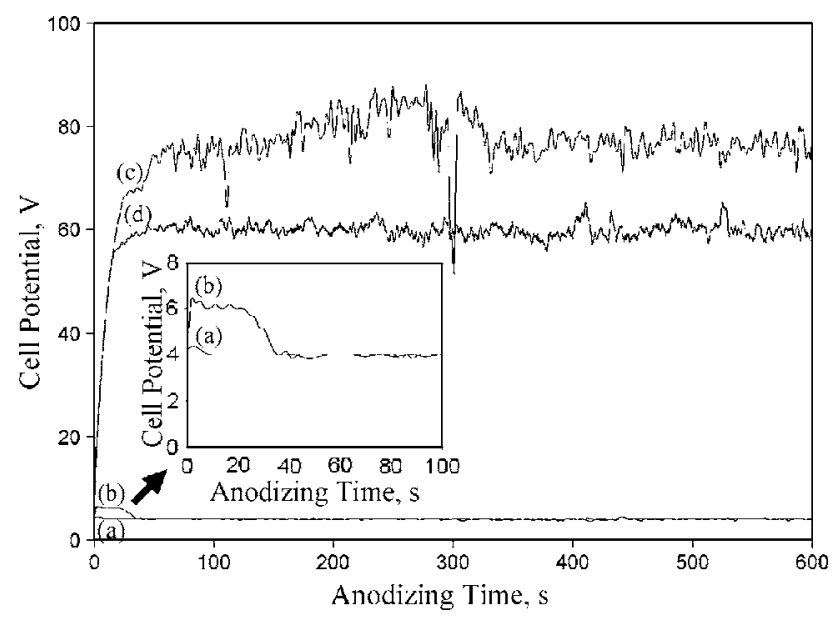

Figure 1. Cell potential as a function of anodization time in the solutions of (a) $\mathrm{KOH}$, (b) $\mathrm{KOH}+\mathrm{Na}_{3} \mathrm{PO}_{4}$, (c) $\mathrm{KOH}+\mathrm{KF}$, and (d) $\mathrm{KOH}+\mathrm{KF}$ $+\mathrm{Na}_{3} \mathrm{PO}_{4}$.

tial increased linearly during the early stages of anodizing up to $\sim 65 \mathrm{~V}$ (Fig. 1c). Thereafter, the potential rose gradually to $75 \mathrm{~V}$ and oscillated there with continued anodizing until the end of the treatment. Concurrent with potential oscillation, intense sparking and gas evolution were observed in the $\mathrm{KOH}+\mathrm{KF}$ solution. This is in good agreement with the fact that the formation of anodic films on magnesium in the fluoride-containing solution relies largely on sparking. ${ }^{2,21}$ When both the $\mathrm{KF}$ and $\mathrm{Na}_{3} \mathrm{PO}_{4}$ were added to the solution, the potential also exhibited an early linear increase to around $55 \mathrm{~V}$ (Fig. 1d), followed by an oscillation at around $60 \mathrm{~V}$. This potential at which sparking occurred agrees well with the literature studying the galvanostatic anodization of $\mathrm{Mg}-\mathrm{Al}$ alloys in the $\mathrm{KOH}$ solution containing fluoride and phosphate ions. ${ }^{13,16}$ Figure 1 also shows that the potential oscillation in the $\mathrm{KOH}+\mathrm{KF}$ $+\mathrm{Na}_{3} \mathrm{PO}_{4}$ solution was less than that in the $\mathrm{KOH}+\mathrm{KF}$ solution. Furthermore, it is apparent that fluoride ions, but not phosphate ions, are necessary for inducing sparks on the plate anodized galvanostatically at $10 \mathrm{~mA} \mathrm{~cm}^{-2}$ in the $\mathrm{KOH}$ solution.

Surface morphology and composition.-Figure 2a shows the overall morphology of an AZ31 plate anodized in the $\mathrm{KOH}$ solution. Scratches formed during mechanical polishing were still visible, although several white spots seen under SEM were observed. The anodic film seemed to be very thin because scratches were still visible. A magnified view of the white spots in Fig. 2a revealed the presence of cracks (Fig. 2b). EDS analysis revealed that both the regions with and without white spots were composed of magnesium and oxygen species (not shown). Because more oxygen was detected in the region dotted with white spots, the anodic film in the white spot region was apparently thicker than that in the region without white spots.

Insignificant change in surface morphology was observed when $\mathrm{Na}_{3} \mathrm{PO}_{4}$ was added to the $\mathrm{KOH}$ solution. Scratches and white spots remained the main features observed on a plate anodized in the $\mathrm{KOH}+\mathrm{Na}_{3} \mathrm{PO}_{4}$ solution. However, compared to the plate anodized in the $\mathrm{KOH}$ solution, more regions dotted with white spots were observed on the plate anodized in the $\mathrm{KOH}+\mathrm{Na}_{3} \mathrm{PO}_{4}$. Again, cracks were frequently observed in the regions dotted with white spots (Fig. 3).

The surface of an AZ31 plate anodized in the $\mathrm{KOH}+\mathrm{KF}$ solution consisted of the region with discernible scratches and the region where scratches had been etched out during anodizing. The region, on which scratches had been etched out, contained microcraters, as indicated by the arrow in Fig. 4. These microcraters seem to be associated with the dielectric breakdown and subsequent sparking, as microcraters were not observed on the plate of which cell poten-
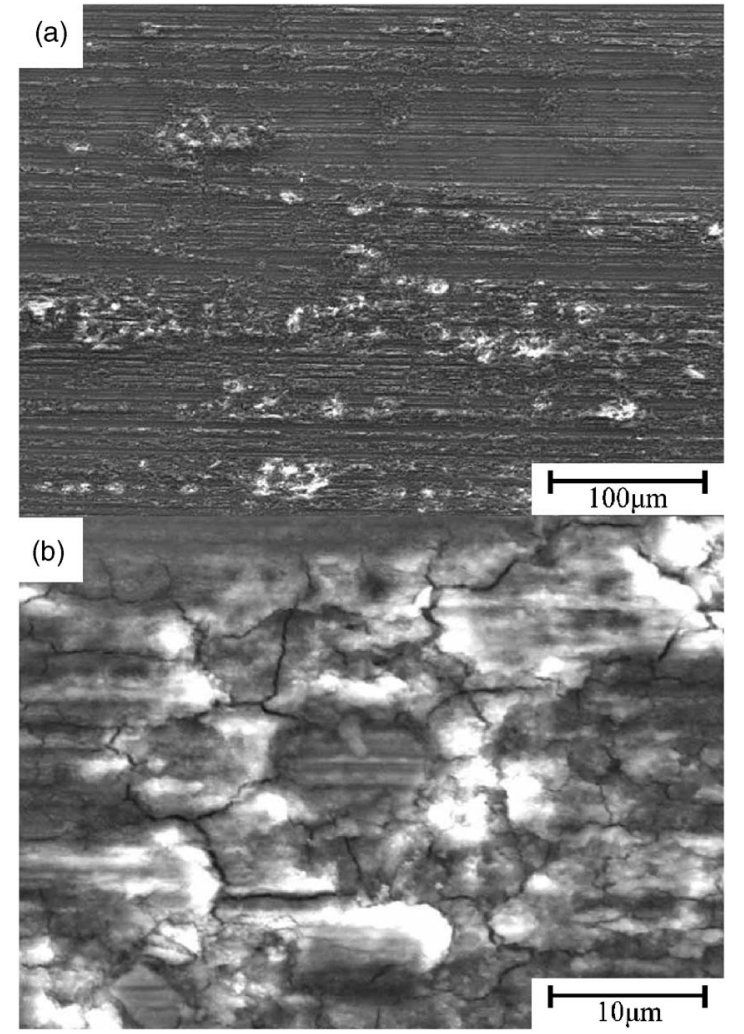

Figure 2. Surface morphology of an AZ31 plate after 10 min of anodizing in the $\mathrm{KOH}$ solution. (a) The surface consists of the region with scratches and the region dotted with white spots. (b) A close-up view of white spots.

tial was relatively low during anodizing. Adding $\mathrm{Na}_{3} \mathrm{PO}_{4}$ to the $\mathrm{KOH}+\mathrm{KF}$ solution resulted in more regions dotted with white spots, while suppressed the etching out of the plate. Figure 5 shows these white spots contained relatively large craters (marked by the arrow). Meanwhile, the relatively flat areas, on which the scratches were still discernible, also contained many relatively small craters (marked by the double arrows).

XRD analysis. - Figure 6a shows the XRD pattern of an AZ31 plate anodized in the $\mathrm{KOH}$ solution. In addition to the peaks from the magnesium substrate, two peaks in this figure can be assigned as magnesium hydroxide, indicating that the anodic film is presumably the magnesium hydroxide. This is in good agreement with the literature studying the anodization of magnesium in the solution solely

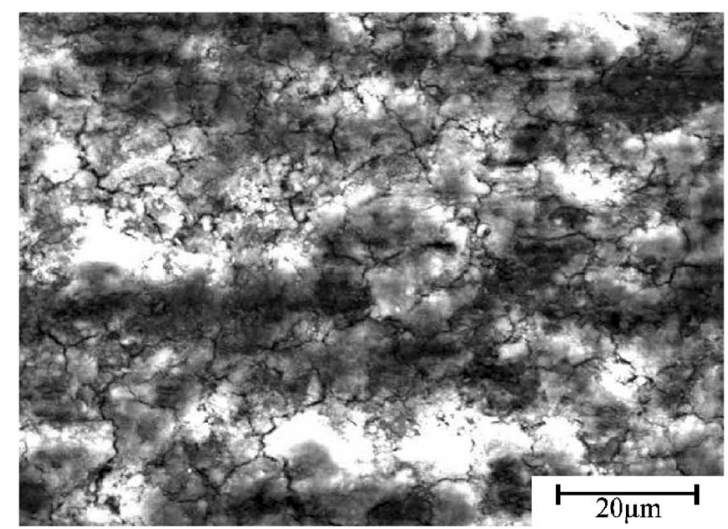

Figure 3. Surface morphology of an AZ31 plate after 10 min of anodizing in the $\mathrm{KOH}+\mathrm{Na}_{3} \mathrm{PO}_{4}$ solution. 


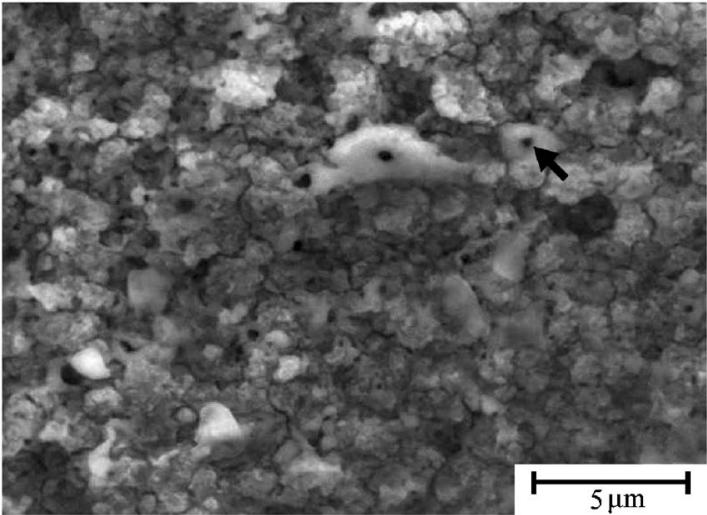

Figure 4. Surface morphology of an AZ31 plate after 10 min of anodizing in the $\mathrm{KOH}+\mathrm{KF}$ solution.

composed of $\mathrm{KOH}^{2,11,12}$ Moreover, the peaks associated with magnesium hydroxide were relatively broadened, suggesting the anodic film had poor crystallinity. Insignificant changes in the XRD patterns were observed as $\mathrm{Na}_{3} \mathrm{PO}_{4}$ was added to $\mathrm{KOH}$ solution (Fig. $6 b)$. In contrast, instead of magnesium hydroxide, magnesium oxide was the primary constituent of the anodic film formed in the solution containing $\mathrm{KOH}$ and $\mathrm{KF}$ (Fig. 7a). Moreover, the magnesium oxide exhibited better crystallinity than the magnesium hydroxide, as illustrated by comparing Fig. 7 with Fig. 6 . The anodic film was still composed of magnesium oxide in the $\mathrm{KOH}+\mathrm{KF}+\mathrm{Na}_{3} \mathrm{PO}_{4}$ solution (Fig. 7b)

Cross-sectional TEM characterization.- Figure 8a and b show the cross-section of an AZ31 plate anodized in the $\mathrm{KOH}$ solution. In some regions, the anodic film solely comprised a porous layer (Fig. $8 \mathrm{a})$, while in others the anodic film consisted of two layers-a porous inner layer directly contacting the substrate and a cellular overlay containing cylindrical pores oriented normal to the metal/film interface (Fig. 8b). The SAD pattern (inset in Fig. 8b) of the porous layer contained diffused halos, indicating this layer had poor crystallinity. The SAD pattern taken from the overlay also contained diffused halos (not shown here). EDS analyses revealed that both the porous inner layer and cellular overlay had a similar composition. Both contained magnesium, oxygen and aluminum species, while the porous layer had more aluminum species than the cellular overlay, as shown in Fig. 8c and d.

The anodic film formed in the $\mathrm{KOH}+\mathrm{Na}_{3} \mathrm{PO}_{4}$ solution also comprised a porous inner layer and a relatively thick overlay (Fig. 9a). Microcracks were frequently observed in the overlay. The po-

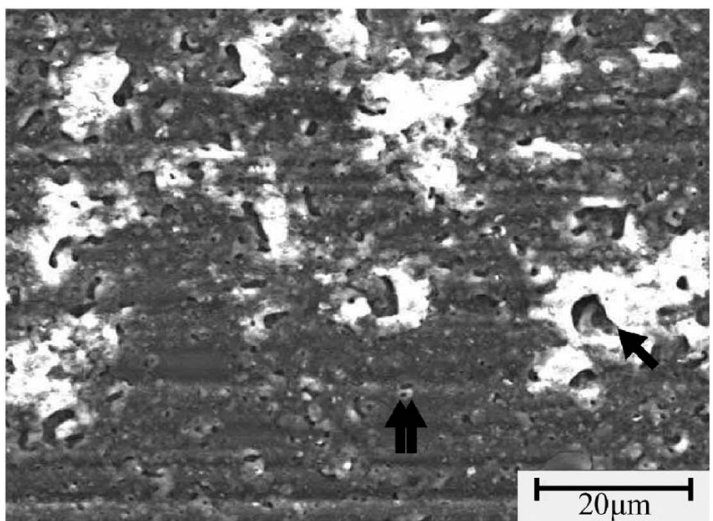

Figure 5. Surface morphology of an AZ31 plate after 10 min of anodizing in the $\mathrm{KOH}+\mathrm{Na}_{3} \mathrm{PO}_{4}+\mathrm{KF}$ solution.

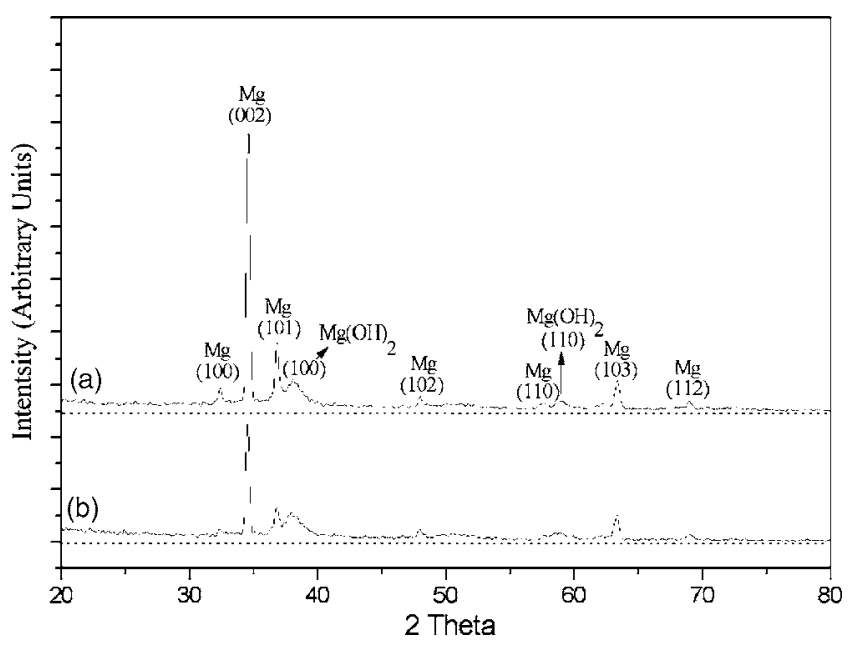

Figure 6. XRD patterns of AZ31 plates anodized in the (a) $\mathrm{KOH}$ and (b) $\mathrm{KOH}+\mathrm{Na}_{3} \mathrm{PO}_{4}$ solutions, respectively.

rous layer and the overlay had a similar composition. Both were mainly composed of magnesium and oxygen species, and trace of phosphorus and aluminum species (Fig. 9b).

Figure 10a shows that the anodic film formed in the $\mathrm{KOH}$ $+\mathrm{KF}$ solution consisted of a compact inner layer contacting the substrate and a major overlay. The inner layer contained significant amounts of fluorine species in addition to magnesium, oxygen, and aluminum (Fig. 10b). The major overlay contained magnesium and oxygen species and traces of aluminum and fluorine (Fig. 10c). The SAD pattern revealed that the major overlay was crystalline magnesium oxide.

Figure 11a shows the cross-sectional TEM of a plate anodized in the $\mathrm{KOH}+\mathrm{KF}+\mathrm{Na}_{3} \mathrm{PO}_{4}$ solution. The anodic film contained many craters of diameters in the range of 0.2 to $1 \mu \mathrm{m}$. Figure $11 \mathrm{~b}$ and $\mathrm{c}$ show the EDS spectrums taken from the wall and base of a crater, respectively, while Fig. 11d and e were taken inside the crater. Fluorine was detected only on the area adjacent to the substrate, and phosphorus was detected mainly on the wall and base of a crater. In contrast, the material inside the crater contained significant oxygen and magnesium species, but only traces of phosphorus and aluminum.

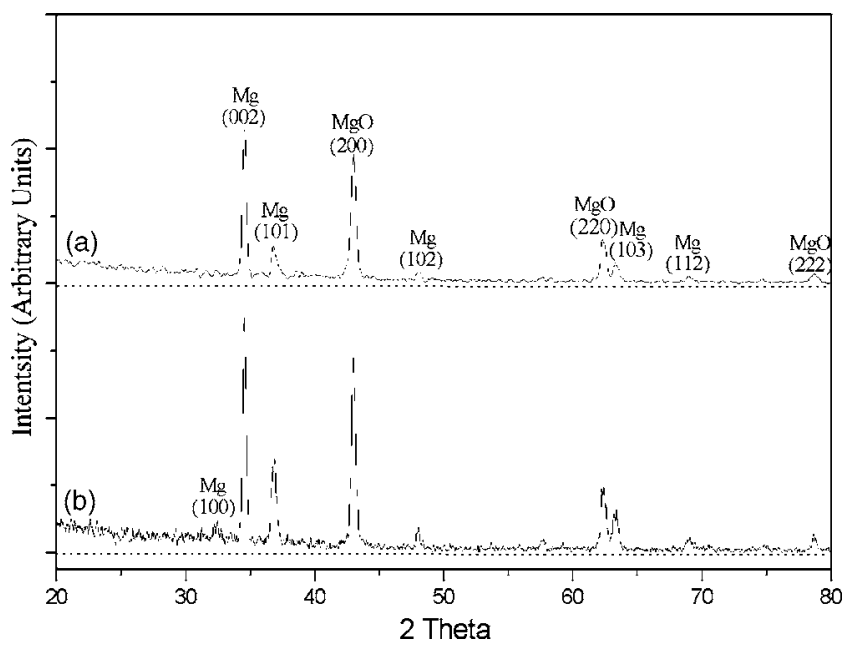

Figure 7. XRD patterns of AZ31 plates anodized in the (a) $\mathrm{KOH}+\mathrm{KF}$ and (b) $\mathrm{KOH}+\mathrm{KF}+\mathrm{Na}_{3} \mathrm{PO}_{4}$ solutions, respectively. 


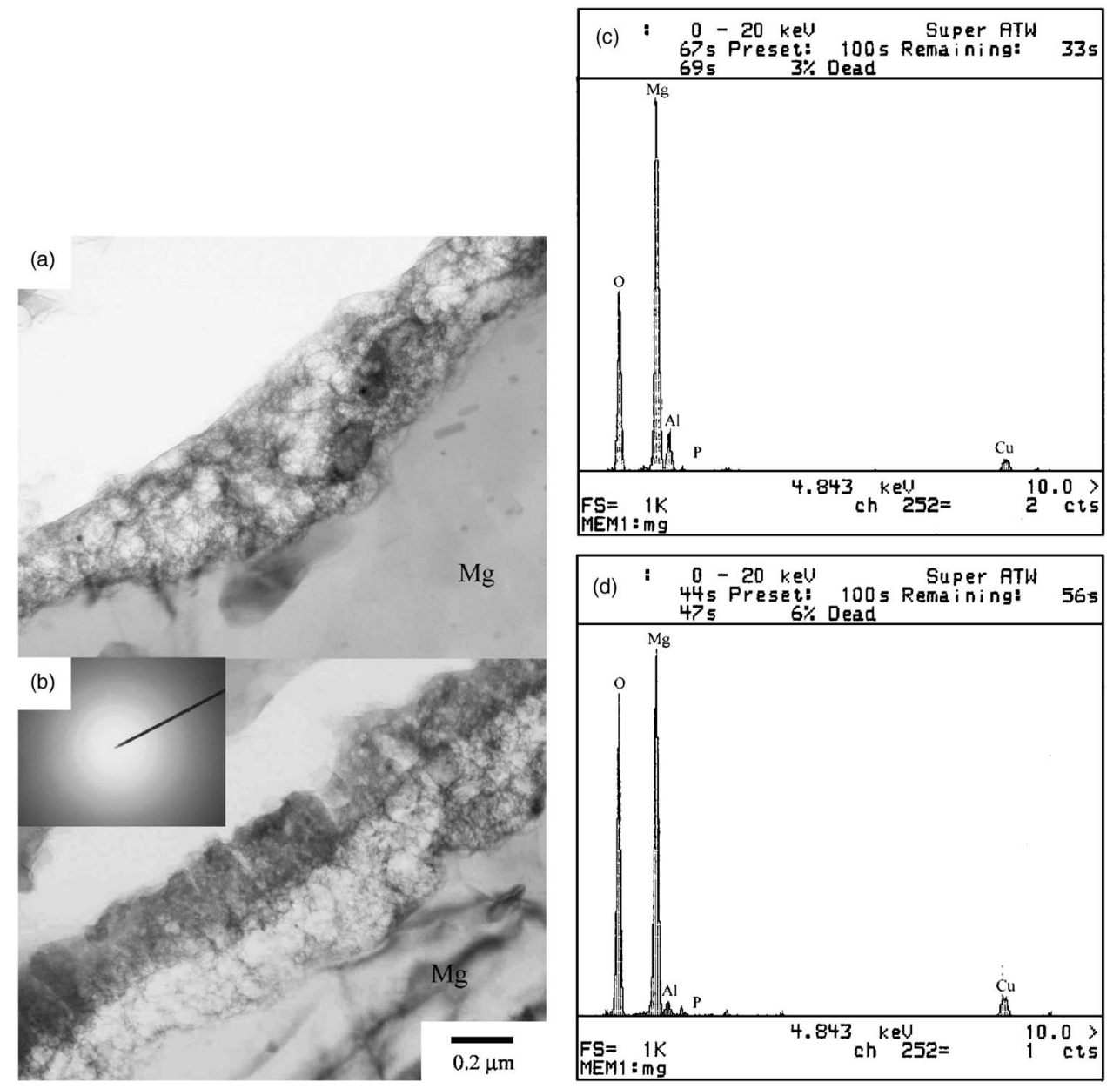

Figure 8. Cross-sectional TEM of an AZ31 plate after $10 \mathrm{~min}$ of anodizing in the $\mathrm{KOH}$ solution. (a) The anodic film solely consists of a porous layer adjacent to the substrate. (b) The anodic film comprises a porous inner layer and a cellular outer layer. (c and d) The EDS spectrums taken from the porous inner layer and cellular outer layer, respectively.

\section{Discussion}

Anodic film formed in the $\mathrm{KOH}$ solution.- The cell potential is around $3 \mathrm{~V}$ when an AZ31 plate is anodized at $10 \mathrm{~mA} \mathrm{~cm}$ in the $\mathrm{KOH}$ solution, and sparks were not observed throughout anodizing. This relatively low potential response suggests that the anodic film has a high ionic conductivity, in consistence with the porous nature of the film shown in Fig. 8a. Apparently, the electric field imposed by the potential is not enough for the formation of sparks between the anode and the cathode.

The present anodic film is primarily the magnesium hydroxide with poor crystallinity. This can be explained by the fact that magnesium hydroxide is thermodynamically more favored over magnesium oxide, as illustrated by their Gibbs free energy of formation (Table I). ${ }^{22}$ Furthermore, magnesium anodized in a $1 \mathrm{M} \mathrm{KOH}$ solution at voltage less than $3 \mathrm{~V}$ has been shown to become passive by the presence of magnesium hydroxide, ${ }^{11,12}$ which was considered to transform from the magnesium oxide layer formed during the beginning of anodization. ${ }^{11}$

Although the anodic film formed in the $\mathrm{KOH}$ is composed of magnesium hydroxide, it displays two different morphologies when viewed via cross-sectional TEM. The inner layer directly contacts the substrate and is more porous than the outer layer. Furthermore, the inner layer/substrate interface presumably propagates into the substrate during anodizing (Fig. 8a and b). This indicates that the growth of the inner layer occurs primarily at the metal/film interface. Furthermore, the porous nature of the inner layer might be due to oxygen evolution taking place in alkaline solutions at intermediate voltages when sparking is absent. ${ }^{2,13,14}$

Because the cell potential is only around $3 \mathrm{~V}$ and the inner layer is highly porous, the present porous inner layer is not likely to arise from counter migration of metal cations and $\mathrm{O}^{2-}$ ions, which has been shown to play an important role in the growth of the inner barrier layer on anodic aluminum and tantalum. ${ }^{19,23,24}$ Instead, the growth of the present porous layer may proceed via the direction oxidation of magnesium in the $\mathrm{KOH}$ solution. That is, when the magnesium substrate is immersed in a strong alkaline electrolyte, its surface becomes passive rapidly by the formation of magnesium hydroxide $^{25}$

$$
\mathrm{Mg}+2 \mathrm{OH}^{-} \rightarrow \mathrm{Mg}(\mathrm{OH})_{2}+2 \mathrm{e}^{-}
$$

The electric field applied then enhances the ejection of $\mathrm{Mg}^{2+}$ ions outward, while assisting the inward migration and subsequent adsorption of $\mathrm{OH}^{-}$ions on the substrate, allowing the growth of the inner layer into the substrate. The porous nature of the inner layer also facilitates counter migration of $\mathrm{Mg}^{2+}$ and $\mathrm{OH}^{-}$ions under the applied electric field.

In addition to the porous inner layer, the present anodic film also consists of a cellular outer layer. This cellular layer contains cylindrical pores, which, to some extent, are oriented normal to the metal/ film interface. This cellular morphology is similar to that of the porous anodic alumina film, which usually nucleates on top of a compact barrier layer. ${ }^{1,26}$ In contrast, the inner layer beneath the present cellular layer is highly porous. Further study is necessary to elucidate why the cellular outer layer develops on top of the porous inner layer.

Effect of fluoride ions. - The striking effect of adding $\mathrm{F}^{-}$ions in $\mathrm{KOH}$ and $\mathrm{KOH}+\mathrm{Na}_{3} \mathrm{PO}_{4}$ solutions is to induce sparks on the magnesium substrate during galvanostatic anodizing. This is in good agreement with the literature illustrating that the anodic film on magnesium anodized in fluoride solutions relies largely on a spark- 

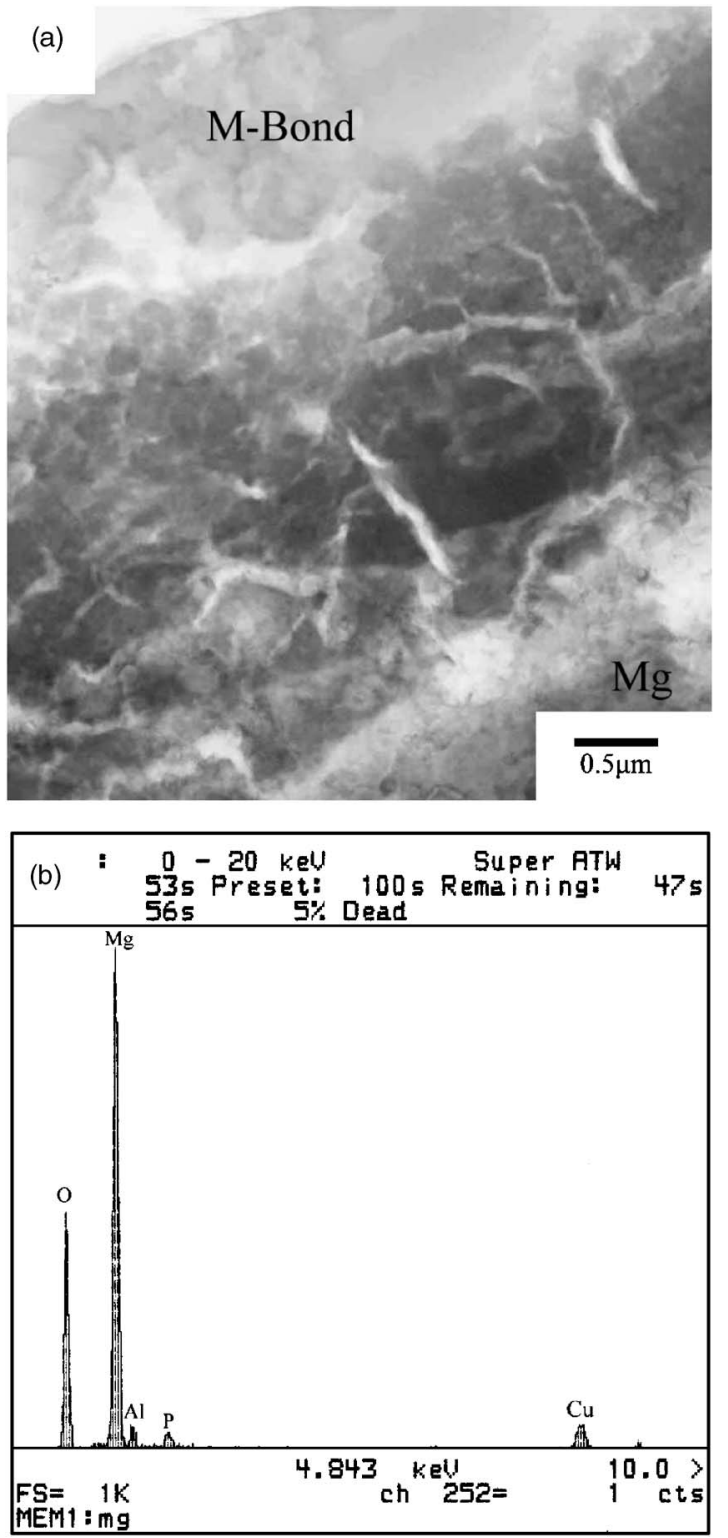

Figure 9. Cross-sectional TEM of an AZ31 plate after 10 min of anodizing in the $\mathrm{KOH}+\mathrm{Na}_{3} \mathrm{PO}_{4}$ solution. (a) The anodic film consists of a porous inner layer and an outer layer with cracks. (b) The EDS spectrum taken from the outer layer.

ing process. ${ }^{2,21}$ Sparking during anodizing is known to be due to the dielectric breakdown of a compact film on metal. ${ }^{4,9,13-17,27}$ In the fluoride-containing solution, this compact layer on magnesium has been reported to be magnesium fluoride, ${ }^{2}$ although direct observation of a magnesium fluoride layer is still absent in the literature. Nevertheless, magnesium fluoride is indeed thermodynamically more stable than magnesium hydroxide and oxide (Table I). However, the layer solely composed of magnesium fluoride was not observed in the present study. Instead, the compact inner layer on the plate anodized in the solution with the addition of KF contains magnesium, oxygen, and fluorine species. It is likely that the compact layer consists of magnesium oxide and fluoride. Therefore, the magnesium fluoride layer, if it forms during the early stages of anodizing, can transform to a mixture of magnesium oxide and fluoride via counter migration of $\mathrm{Mg}^{2+}$ and $\mathrm{O}^{2-}$ ions. Once sparking commences, plasma electrolytic reaction proceeds, ${ }^{27}$ thereby giving rise to the formation of the compact layer composed of magnesium, oxygen and fluorine.
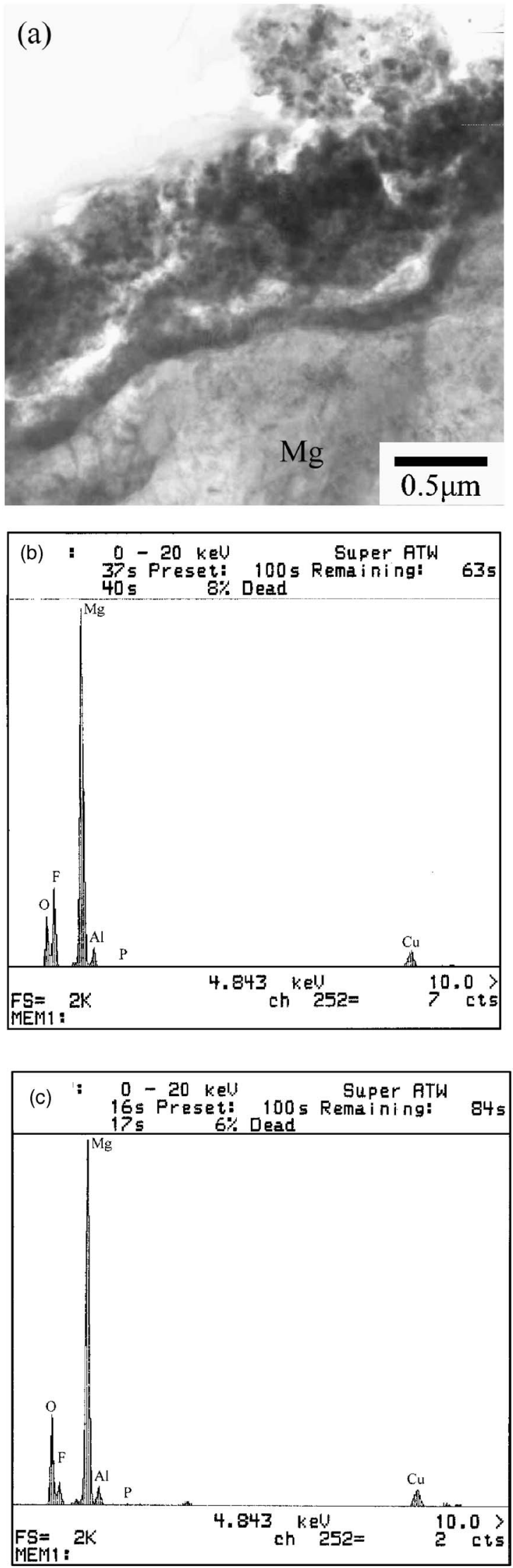

Figure 10. Cross-sectional TEM of an AZ31 plate after 10 min of anodizing in the $\mathrm{KOH}+\mathrm{KF}$ solution. (a) The anodic film is composed of an inner compact layer and a relatively thick outer layer. (b and c) The EDS spectrums taken from the inner and outer layers, respectively. 

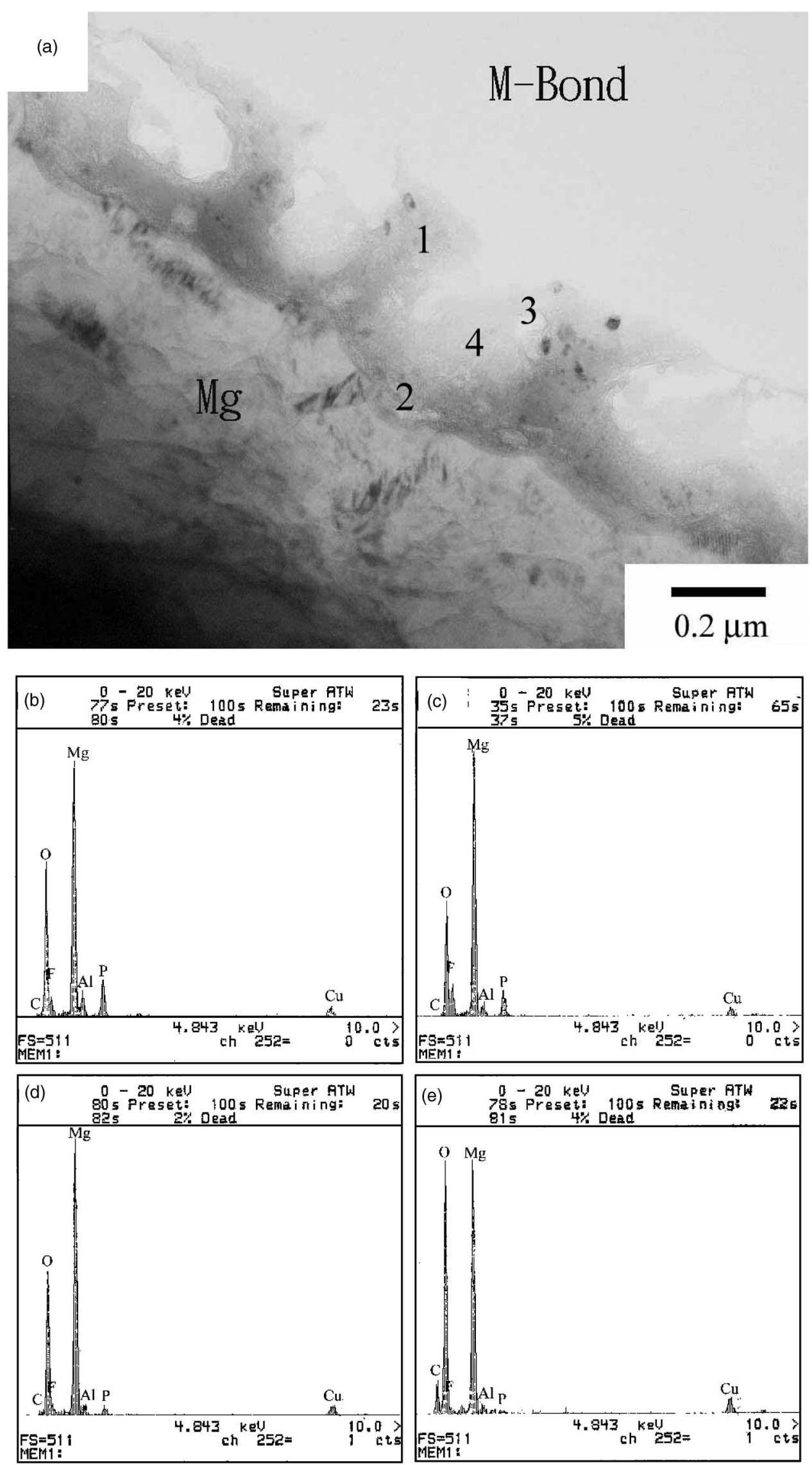

Figure 11. Cross-sectional TEM of an AZ31 plate after 10 min of anodizing in the $\mathrm{KOH}+\mathrm{KF}+\mathrm{Na}_{3} \mathrm{PO}_{4}$ solution. (a) The anodic film is composed of a inner compact layer and an outer layer dotted with craters. ( $b$ and c) The EDS spectrums taken from the wall (marked as 1 ) and base (marked as 2 ) of a crater, respectively. (d and e) The EDS spectrums taken from the material inside a crater (marked as 3 and 4, respectively). 
Table I. The entropy, standard enthalpy of formation, and standard free energy of formation at $298.15 \mathrm{~K}$ for magnesium oxide, hydroxide, and fluoride.

\begin{tabular}{lccc} 
Compounds & $\begin{array}{c}\text { Enthalpy of } \\
\text { formation } \\
\left(\mathrm{kJ} \mathrm{mol}^{-1}\right)\end{array}$ & $\begin{array}{c}\text { Entropy } \\
\left(\mathrm{kJ} \mathrm{K}^{-1} \mathrm{~mol}^{-1}\right)\end{array}$ & $\begin{array}{c}\text { Gibbs free energy } \\
\text { of formation } \\
\left(\mathrm{kJ} \mathrm{mol}^{-1}\right)\end{array}$ \\
\hline $\mathrm{MgO}$ & -601.6 & 27 & -569.3 \\
$\mathrm{Mg}(\mathrm{OH})_{2}$ & -924.5 & 63.2 & -833.5 \\
$\mathrm{MgF}_{2}$ & -1124.2 & 57.2 & -1071.1
\end{tabular}

In the $\mathrm{KOH}+\mathrm{KF}$ solution, the thickness of the compact layer shown in Fig. 10a is $\sim 0.2 \mu \mathrm{m}$ after $10 \mathrm{~min}$ of anodizing. Taking the potential as $75 \mathrm{~V}$ (Fig. 1), the electric field across the compact layer is around $3.5 \times 10^{6} \mathrm{~V} \mathrm{~cm}^{-1}$. In the $\mathrm{KOH}+\mathrm{KF}+\mathrm{Na}_{3} \mathrm{PO}_{4}$ solution, the thickness of the compact layer is around $50 \mathrm{~nm}$ and the cell potential is around $60 \mathrm{~V}$, giving rise to an electric field of around $1.2 \times 10^{7} \mathrm{~V} \mathrm{~cm}^{-1}$. The electric field associated with the compact layer observed in the present study is comparable to that measured in an alkaline silicate solution, ${ }^{9}$ while it is less than that observed in the Dow 17 solution. ${ }^{28}$ This indicates that the thickness and nature of the compact (i.e., barrier) layer on anodized magnesium markedly rely on the composition of the electrolyte. Therefore, the difference in the thickness and dielectric strength of the compact layer formed in $\mathrm{KOH}+\mathrm{KF}$ and $\mathrm{KOH}+\mathrm{KF}+\mathrm{Na}_{3} \mathrm{PO}_{4}$ solutions can be ascribed to the presence of $\mathrm{PO}_{4}^{3-}$ ions, which potentially modify the nature of the compact layer.

Concurrent with the formation of compact layer in the presence of $\mathrm{F}^{-}$, the cell potential increases with continued anodizing until the dielectric breakdown of the compact layer commences. Heat generated by sparks can, on one hand, lead to the dissolution of the surface film and the substrate, and the ionization of the electrolyte, giving rise to a plasma electrolytic process. ${ }^{27}$ On the other hand; thermal stress due to heat generation on the film and its dissipation to the solution can influence the integrity of the anodic film. The resultant film is primarily the crystalline magnesium oxide with incorporation of the species from the electrolyte. Both the relatively high electric field and the heat generated by sparks contribute to the formation of crystalline magnesium oxide. This magnesium oxide film can also arise from dehydration of magnesium hydroxide (Reaction 2), crystallization of the amorphous layer formed prior to dielectric breakdown, ${ }^{14}$ or the direct reaction between $\mathrm{Mg}^{2+}$ and $\mathrm{O}^{2-}$ in the solution, in which $\mathrm{Mg}^{2+}$ is resulted from dissolution of the substrate and $\mathrm{O}^{2-}$ from field-assisted deprotonation of $\mathrm{OH}^{-}$and $\mathrm{H}_{2} \mathrm{O}$. Because Reaction 2 is an endothermic reaction, the high temperature environment created by sparks favors the formation of magnesium oxide

$$
\mathrm{Mg}(\mathrm{OH})_{2} \rightarrow \mathrm{MgO}+\mathrm{H}_{2} \mathrm{O}
$$

The craters which result from sparking do not completely transverse the coating, as shown in Fig. 10a and 11a. Instead, a compact layer was observed in between the crater-containing outer layer and the substrate. It has been shown that the corrosion resistance of the anodic film formed via sparking process shows a good correlation with the barrier film thickness. ${ }^{4}$ This is because the compact barrier layer enhances the corrosion resistance of the alloy by preventing the magnesium substrate from the direct contact with the aggressive environment. ${ }^{3}$ Moreover, sealing the anodic film with paints can further improve the corrosion resistance of magnesium alloys. ${ }^{3}$

Effect of phosphate ions. - Adding $\mathrm{Na}_{3} \mathrm{PO}_{4}$ in the $\mathrm{KOH}$ solution hardly modifies the potential response during anodizing. This is consistent with the fact that a compact layer is absent from the surface of a plate anodized in the $\mathrm{KOH}+\mathrm{Na}_{3} \mathrm{PO}_{4}$ solution (Fig. 9a). Nevertheless, $\mathrm{PO}_{4}^{3-}$ ions in the solution result in thicker anodic films. This is presumably due to the precipitation of magnesium phosphate $\left(\mathrm{Mg}_{3}\left(\mathrm{PO}_{4}\right)_{2}\right)$. Because of the relatively small solubility product constant $\left(\mathrm{K}_{\mathrm{sp}} \sim 9.86 \times 10^{-25}\right.$ for $\mathrm{Mg}_{3}\left(\mathrm{PO}_{4}\right)_{2}$ at $\left.25^{\circ} \mathrm{C}\right),{ }^{21}$
$\mathrm{Mg}^{2+}$ dissolved from the substrate is ready to precipitate as $\mathrm{Mg}_{3}\left(\mathrm{PO}_{4}\right)_{2}$ in the presence of $\mathrm{PO}_{4}^{3-}$ ions. Furthermore, the precipitation of $\mathrm{Mg}_{3}\left(\mathrm{PO}_{4}\right)_{2}$ can be rather random depending on the concentration of $\mathrm{Mg}^{2+}$ and $\mathrm{PO}_{4}^{3-}$ ions. Consequently, phosphorus species are uniformly distributed in the anodic film. In contrast, when aluminum is anodized in phosphate solutions at a constant current density of $10 \mathrm{~mA} \mathrm{~cm}^{-2}$ to $50 \mathrm{~V}$, phosphorus species are mainly detected on the outer layer of the anodic film, leaving a pure alumina inner layer residing in between the outer layer and the aluminum substrate. $^{29}$

Unlike the uniform distribution in the anodic film formed in the solution where sparks are absent, phosphorus species are distributed preferentially on the walls and bases of craters for the electrolyte (i.e., $\mathrm{KOH}+\mathrm{KF}+\mathrm{Na}_{3} \mathrm{PO}_{4}$ ) in which sparking occurs. Moreover, the interiors of craters are filled with materials composed of magnesium and oxygen species, but free of phosphorus species (Fig. 11). It is apparent that sparking not only promotes the formation of crystalline oxide film, but also modifies the composition and element distribution of the anodic film. For example, more phosphorus species can be incorporated into the anodic film during sparking, as shown by comparing Fig. $9 \mathrm{~b}$ to $11 \mathrm{~b}$ and $\mathrm{c}$. In an alkaline phosphate solution, the atomic ratio of phosphorus to oxygen of the anodic film on magnesium has been shown to increase markedly after dielectric breakdown. $^{9}$

\section{Conclusions}

This present study investigated the effects of $\mathrm{F}^{-}$and $\mathrm{PO}_{4}^{3-}$ ions on the anodizing behavior and microstructure of the anodic film on AZ31 magnesium alloys in an alkaline solution. During galvanostatic anodizing at $10 \mathrm{~mA} \mathrm{~cm}-2$ in the $\mathrm{KOH}$ solution, the plate became passive by the presence of magnesium hydroxide. This magnesium hydroxide consisted of two layers - a porous inner layer and a cellular outer layer. Because both layers were relatively porous, the potential of the cell was relatively low $(\sim 3 \mathrm{~V})$ throughout anodizing. $\mathrm{PO}_{4}^{3-}$ ions in the $\mathrm{KOH}$ solution resulted in thicker magnesium hydroxide, but hardly affected the potential response of the cell. In contrast, in the solution containing $\mathrm{F}^{-}$ions, the potential rose abruptly in the beginning of anodizing, followed by random oscillations, when intense sparking occurred and scanned throughout the surface of the plate. This sparking was due to the dielectric breakdown of a compact layer composed of fluorine, oxygen, and magnesium. Furthermore, the anodic film formed with and without sparking was mainly the magnesium oxide and hydroxide, respectively. The magnesium hydroxide had poor crystallinity, whereas the oxide counterpart exhibited a crystalline structure.

For the solution, in which sparks were absent, phosphorus species were distributed uniformly in the anodic film, presumably in the form of $\mathrm{Mg}_{3}\left(\mathrm{PO}_{4}\right)_{2}$. However, in the solution where sparking occurred, $\mathrm{PO}_{4}^{3-}$ ions in the solution promoted the formation of numerous craters. The phosphorus species were detected predominantly in the walls and bases of craters. Unlike the distribution of phosphorus, fluorine species were detected mainly in the compact layer directly contacting the substrate.

\section{Acknowledgments}

The authors thank the National Science Council of the Republic of China for financially supporting this research under grant no. 922216E002017. This study made use of the Electron Microscopes of National Taiwan University and National Sun Yat-sen University, supported by the National Science Council, Republic of China.

National Taiwan University assisted in meeting the publication costs of this article.

\section{References}

1. B. J. Weber, Electrolytic and Chemical Conversion Coatings, 1st ed., Portcullis Press Ltd., Poland (1976).

2. M. Takaya, Aluminum, 65, 1244 (1989)

3. A. J. Zozulin and D. E. Bartak, Met. Finish., 92, 39 (1994).

4. V. Birss, S. Xia, R. Yue, and R. G. Rateick, Jr., J. Electrochem. Soc., 151, B1 
(2004).

5. J. E. Gray and B. Luan, J. Alloys Compd., 336, 88 (2002).

6. The Dow Chemical Company, GB Pat. 762,195 (1956).

7. H. A. Evangelides, U. S. Pat. 2,723,952 (1955).

8. P. Kurze, Metalloberflache, 48, 104 (1994).

9. F. A. Bonilla, A. Berkani, Y. Liu, P. Skeldon, G. E. Thompson, H. Habazaki, K. Shimizu, C. John, and K. Stevens, J. Electrochem. Soc., 149, B4 (2002).

10. A. S. Shatrov, Korroziya: Materialy, Zashchita, 10, 31 (2004).

11. K. Huber, J. Electrochem. Soc., 100, 376 (1953).

12. Y. Mizutani, S. J. Kim, R. Ichino, and M. Okido, Surf. Coat. Technol., 169-170, 143 (2003).

13. O. Khaselev and J. Yahalom, Corros. Sci., 40, 1149 (1998).

14. O. Khaselev and J. Yahalom, J. Electrochem. Soc., 145, 190 (1998).

15. O. Khaselev and J. Yahalom, J. Electrochem. Soc., 146, 1757 (1999).

16. H. Y. Hsiao and W. T. Tsai, Surf. Coat. Technol., 190, 299 (2005).

17. H. Y. Hsiao, H. C. Tsung, and W. T. Tsai, Surf. Coat. Technol., 199, 127 (2005).

18. Y. Zhang, C. Yan, F. Wang, H. Lou, and C. Cao, Surf. Coat. Technol., 161, 36 (2002).
19. R. C. Furneaux, G. E. Thompson, and G. C. Wood, Corros. Sci., 18, 853 (1978)

20. K. Shimizu, K. Kobayashi, G. E. Thompson, G. C. Wood, and P. Skeldon, Philos Trans. R. Soc. London, 354, 213 (1996).

21. A. E. Yaniv and H. Schick, Plating, 58, 1295 (1968).

22. CRC Handbook of Chemistry and Physics, 74th ed., D. R. Lide, Editor, CRC Press, Boca Raton, FL (1993).

23. J. P. S. Pringle, J. Electrochem. Soc., 120, 398 (1973).

24. F. Brown and W. D. Mackinosh, J. Electrochem. Soc., 1120, 1096 (1973)

25. M. Pourbaix, Atlas of Electrochemical Equilibria in Aqueous Solutions, 2nd ed., p. 141, NACE, Houston, TX (1974).

26. F. Keller, M. S. Hunter, and D. L. Robinson, J. Electrochem. Soc., 100, 411 (1953).

27. A. L. Yerokhin, X. Nie, A. Leyland, A. Matthews, and S. J. Dowey, Surf. Coat. Technol., 122, 73 (1999)

28. S. Ono, K. Asami, T. Osaka, and N. Masuko, J. Electrochem. Soc., 143, L62 (1996).

29. H. Takahashi, K. Fujimoto, and M. Nagayama, J. Electrochem. Soc., 135, 1349 (1988). 